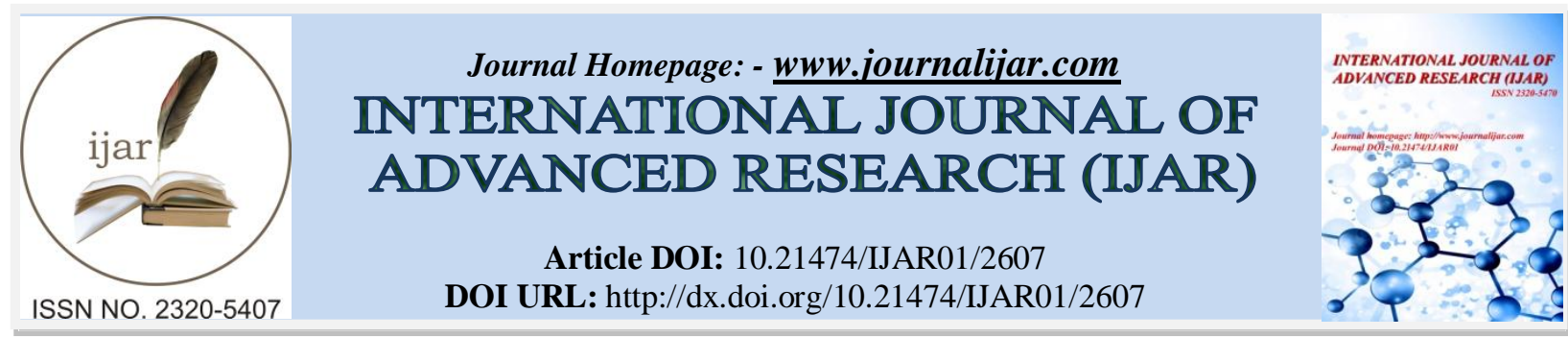

RESEARCH ARTICLE

\title{
PREVALENCE OF SUBCLINICAL HYPOTHYROIDISM IN ELDERLY PATIENTS WITH CARDIOVASCULAR DISEASE.
}

\author{
Mohsen M. Eldarawy ${ }^{1}$, Nearmeen M. Rashad ${ }^{1}$, Ashraf A. Hammam ${ }^{1}$, Fady M. Wadea ${ }^{1}$, Tarek M.H. Ibrahim ${ }^{1}$ \\ ,Ahmed Kh. Alkolaly ${ }^{1}$ and Amal S. El-Shal ${ }^{2}$. \\ 1. Internal Medicine Department, Faculty of Medicine, Zagazig University, Zagazig, Egypt. \\ 2. Medical Biochemistry Department, Faculty of Medicine, Zagazig University, Zagazig, Egypt.
}

\section{Manuscript Info}

Manuscript History

Received: 28 October 2016

Final Accepted: 27 November 2016

Published: December 2016

Key words:-

Subclinical Hypothyroidism, cardiovascular disease, elderly.

\section{Abstract}

Background: The prevalence of sub clinical hypothyroidism $(\mathrm{SCH})$ is relatively high and ranges from $4 \%$ to $20 \%$ in the adult population with more common in elderly. Elderly with SCH had higher risk of incident heart failure. Few studies reported the prevalence of thyroid dysfunction in elderly Egyptians especially coronary heart disease (CHD). The aim of our study was to estimate the prevalence of Subclinical hypothyroidism in elderly cardiac patients and to assess the relation between thyroid function, cardiovascular risk and severity of CHD in elderly.

Methods: cross sectional study included 45 elderly Egyptian patients with cardiovascular disease and 45 healthy elderly subjects as controls. Cardiac patients were subdivided to ischemic $(n=23)$ and hypertensive groups $(\mathrm{n}=22)$, ischemic group subdivided according to number of coronary artery occlusions. Serum level of $\mathrm{FT}_{4}, \mathrm{FT}_{3}, \mathrm{TSH}$, lipid profile, fasting blood glucose were measured.

Results: our results shows that, there were statistically significant higher levels of thyroid stimulating hormone (TSH), lipid profile, systolic and diastolic blood pressure in case group compared to control group. Additionally, There were statistically significant higher levels of TSH in ischemic cardiac group compared to hypertensive cardiac group ( $\mathrm{p}<0.05)$, on the contrary there were no significant different as regard free T3 and T4 levels among studied groups. The prevalence of coronary artery occlusion in ischemic cardiac group was; normal (62.2\%), single vessel disease (24.4\%), two vessel disease $(11.2 \%)$ and three vessel disease $(2.2 \%)$. There was significant positive correlation between TSH levels and the number of coronary artery occlusion .In ischemic cardiac patients, linear regression analysis showed that TSH levels were independently correlated with TC, TG, LDL and HDL (P < 0.05).

Conclusion: the prevalence of subclinical hypothyroidism in all cardiac group was (22\%); in ischemic group (26\%) and in hypertensive group (18\%). Also, there was positive association between Subclinical Hypothyroidism, Hypertension, Dyslipidemia and CHD in elderly Patients.

Corresponding Author:- Mohsen M. Eldarawy.

Address:- Internal Medicine Department, Faculty of Medicine, Zagazig University, Zagazig, Egypt. 
Copy Right, IJAR, 2016,. All rights reserved.

\section{Introduction:-}

Prevalence of elderly worldwide is rapidly accelerating from 461 million aged over 65 years in 2004 to an estimated 2 billion people by 2050 (1).

Subclinical hypothyroidism (SCH), is an elevation of thyroid-stimulating hormone (TSH) levels with a normal free thyroxine (fT4) level, additionally, an increasing amount of evidence indicates that that SCH represents mild thyroid failure (2).

The prevalence of $\mathrm{SCH}$ is relatively high and ranges from $4 \%$ to $20 \%$ in the adult population; women and elderly people are affected more (3). Thyroid hormones act on the heart and vascular system and, as a result, the impact of subclinical thyroid abnormalities on the cardiovascular system has been identified. Subclinical hypothyroidism can lead to impaired systolic and diastolic function (4) and hypothyroidism patients often complain of reduced exercise tolerance (5), also, in hypothyroidism a slower rate of left ventricular relaxation might critically impair ventricular filling during exertion that leads to left ventricular systolic dysfunction (5).

Older people with subclinical hypothyroidism with high CV risk appear to be at an increased risk of incident cardiac failure (6) and subclinical hypothyroidism was found to affect left ventricular function which may be reversed by T4 supplementation (6). A recent cardiac magnetic resonance spectroscopic study demonstrated that early cardiac bioenergetic impairments in patients with subclinical hypothyroidism are reversible with T4 therapy (7).

There is great evidence that high TSH levels or SCH associated with adverse cardiovascular (CV) outcomes. The optimal TSH cutoff values and the definition of SCH are still controversy (8). Screening and treatment of SCH also still controversy. Many studies suggested treatment of SCH in case of pregnancy, infertility, presence of associated symptoms, or have a high risk of progression to overt hypothyroidism (9). To the best of our knowledge, this study is the first study in Egypt that estimated thyroid functions in ischemic heart disease elderly patients. The aim of our study was to estimate the prevalence of Subclinical hypothyroidism in elderly cardiac patients and to assess the correlation between number of coronary blood vessels occluded, cardiovascular risk and thyroid function in elderly.

\section{Subjects and methods:-}

This study included 90 unrelated elderly patients. Subjects were divided into 45 elderly with cardiovascular diseases recruited from diabetes and endocrinology outpatient clinic of Internal Medicine Department in collaboration with cardiology department, Zagazig University Hospitals, Zagazig, Egypt and 45 healthy controls. Cases and controls were matched in age, gender and ethnic origin. Cardiac patients were stratified into two subgroups hypertensive and ischemic. A retrospective analysis was conducted on ischemic elderly group, who underwent coronary angiography at cardiology department of Zagazig University Hospitals, and thus subdivided according to results of coronary angiography into four groups. Subclinical hypothyroidism was defined as a TSH concentration of $>4.20 \mu \mathrm{IU} / \mathrm{L}$ with a normal FT4 and FT3 concentration (9).

All patients were subjected to thorough history taking and full clinical assessment of blood pressure, height, waist circumference (WC), hip circumference (HC), Body mass index (BMI) that was calculated as weight in $\mathrm{kg} / \mathrm{height}$ in (meters $)^{2}$, The decision to perform coronary angiography was based on symptoms consistent with the diagnosis, an abnormal electrocardiogram (ECG), positive findings in standard exercise tests, or abnormal findings in radio nuclear studies.

\section{Exclusion criteria:-}

Elderly patients with history of stroke, respiratory disease, cancer, severe hepatic impairment, patients with renal diseases, acute illness, hormonal therapy, any active inflammatory diseases as well as receiving medications that affect thyroid function tests.

The ethical committee of Faculty of Medicine, Zagazig University approved our study protocol, and all participants assigned written informed consent. 


\section{Blood sampling:-}

Blood samples were drawn from all subjects after an overnight fast and divided into 3 portions: $1 \mathrm{ml}$ of whole blood was collected into tubes containing EDTA, for hemoglobin, hematocrit, HbA1c measurement; $1 \mathrm{ml}$ of whole blood was collected into tubes containing potassium oxalate and sodium fluoride (2:1) for measurement of fasting blood glucose. Sera were separated immediately from remaining part of the sample and stored at $-20{ }^{\circ} \mathrm{C}$ until analysis.

\section{Biochemical measurements:-}

Fasting blood glucose was measured using the glucose oxidase method (Spinreact, Girona, Spain). Total cholesterol, HDL cholesterol, and triglycerides were measured by routine enzymatic methods (Spinreact, Girona, Spain). LDL cholesterol was calculated as follows: LDL-C $=\mathrm{TC}-\mathrm{HDL}-\mathrm{C}-\mathrm{TG} / 5$ Friedewald formula (10).

\section{Immunochemical measurements:-}

The thyroid function assessment was done by measurement of FT3, FT4 and TSH using chemiluminescence immunoassay (CLIA) assay kit provided by (Immunospec Corporation, Canoga Park, CA, USA). The normal reference range for FT3 is $1.8-4.6 \mathrm{pg} / \mathrm{ml}$, for FT4 is $1.0-1.8 \mathrm{ng} / \mathrm{dl}$ and for TSH is $0.3-4.20 \mu \mathrm{IU} / \mathrm{L}$ according to Bemben et al. (11) and Bell et al. (12).

\section{Statistical analysis:-}

Statistical analyses were performed using the Statistical Package for the Social Sciences for Windows (version 22.0; SPSS Inc., Chicago, IL, USA). Data were expressed as (mean \pm standard deviation). One-way analysis of variance (ANOVA) was used when appropriate. Pearson correlation test was done to assess the correlation between TSH levels and number of coronary artery disease. The prevalence of subclinical hypothyroidism in cardiac groups and the number (percentage) of coronary artery occlusion were analyzed by using chi-squared $\left(\mathrm{X}^{2}\right)$. A linear regression analysis was performed to detect the independent correlated parameters with of TSH levels in ischemic cardiac elderly. P-values were considered significant if $<0.05$.

\section{Results:-}

The main groups were a control group which included 45 elderly healthy staff members of both genders; 17 female and 28 male with mean age of $67.78 \pm 2.28$ and mean BMI of $23.35 \pm 1.79$ and a case group which included 45 elderly cardiovascular disease patients "10 subclinical hypothyroidism patients and 35 euthyroid patients" of both genders; 25 female and 20 male with mean age of $67.36 \pm 1.6$ and mean BMI of $23.56 \pm 2.76$

\section{Clinical, Anthropometric and biochemical characteristics of the studied groups:-}

Cardiac elderly patients had significantly higher values of systolic and diastolic blood pressure, fasting blood glucose, total cholesterol and LDL cholesterol as compared to controls ( $\mathrm{p}<0.05)$.Moreover, Our study showed that, there were statistically significant higher levels of TSH in case group compared with control group (1.45 \pm 0.46$)$. On the contrary there were no significant different as regard free T3 and T4 levels among studied groups (table1).

Table 1:- Clinical, Anthropometric and biochemical characteristics of the studied groups.

\begin{tabular}{|l|c|c|c|}
\hline \multicolumn{1}{|c|}{ Variable } & $\begin{array}{c}\text { Healthy Control } \\
(\mathrm{n}=45)\end{array}$ & $\begin{array}{c}\text { Cases } \\
(\mathrm{n}=45)\end{array}$ & P value \\
\hline Body mass index & $23.35 \pm 1.79$ & $23.56 \pm 2.76$ & 0.32 \\
\hline Systolic blood pressure $(\mathrm{mmHg})$ & $79.78 \pm 3.53$ & $87.89 \pm 13.84^{*}$ & $<0.001^{*}$ \\
\hline Diastolic blood pressure $(\mathrm{mmHg})$ & $120.67 \pm 2.74$ & $135.78 \pm 14.81^{*}$ & $<0.001^{*}$ \\
\hline Total cholesterol $(\mathrm{mg} / \mathrm{dl})$ & $165.78 \pm 23.67$ & $184.89 \pm 25.91^{*}$ & $<0.001^{*}$ \\
\hline Triglycerides $(\mathrm{mg} / \mathrm{dl})$ & $134.64 \pm 31.31$ & $134.53 \pm 32.76$ & 0.10 \\
\hline LDL cholesterol $(\mathrm{mg} / \mathrm{dl})$ & $94.78 \pm 17.54$ & $114.8 \pm 29^{*}$ & $<0.001^{*}$ \\
\hline HDL cholesterol $(\mathrm{mg} / \mathrm{dl})$ & $43.78 \pm 4.79$ & $44 \pm 13.36$ & 0.02 \\
\hline FBG & $85.95 \pm 3.025$ & $87.05 \pm 4.6$ & 0.23 \\
\hline TSH $(\mu \mathrm{IU} / \mathrm{ml})$ & $1.45 \pm 0.46$ & $4.86 \pm 1.87$ & $<0.001^{*}$ \\
\hline FT4(ng/dl) & $14.49 \pm 1.91$ & $14.42 \pm 1.79$ & 0.17 \\
\hline FT3(pg/ml) & $7.02 \pm 1.14$ & $7.49 \pm 1.01$ & 0.1 \\
\hline
\end{tabular}


BMI, body mass index; FBG, fasting blood glucose; LDL-C, low density lipoprotein cholesterol; HDL-C, high density lipoprotein cholesterol. TSH ,thyroid stimulating hormone; FT3 free triidothyronine ,FT4; free thyroxine , Significant $\mathrm{P}$ values $(\mathrm{P}<0.05)$ when compared with control group.

Clinical and biochemical characteristics of the cardiac groups:-

In hypertensive group $(\mathrm{n}=22)$, there were higher levels of systolic and diastolic blood pressure than ischemic group $(\mathrm{n}=23)$.

Table 2:- clinical and anthropometric parameters of hypertensive and ischemic elderly cardiac group

\begin{tabular}{|l|c|c|c|}
\hline \multicolumn{1}{|c|}{ Variable } & $\begin{array}{c}\text { Ischemic group } \\
(\mathrm{n}=23)\end{array}$ & $\begin{array}{c}\text { HTN group } \\
(\mathrm{n}=22)\end{array}$ & P value \\
\hline Systolic blood pressure $(\mathrm{mmHg})$ & $126.52 \pm 10.70$ & $145.45 \pm 12.14^{*}$ & $<0.001^{*}$ \\
\hline Diastolic blood pressure $(\mathrm{mmHg})$ & 76.958 .75 & $99.31 \pm 7.28^{*}$ & $<0.001^{*}$ \\
\hline Total cholesterol $(\mathrm{mg} / \mathrm{dl})$ & $192.04 \pm 24.60$ & $145.45 \pm 12.14$ & 1.95 \\
\hline Triglycerides $(\mathrm{mg} / \mathrm{dl})$ & $127.91 \pm 32.96$ & $141.45 \pm 31.80$ & 1.40 \\
\hline LDL cholesterol $(\mathrm{mg} / \mathrm{dl})$ & $120.70 \pm 29.86$ & $108.64 \pm 27.38$ & 1.41 \\
\hline HDL cholesterol $(\mathrm{mg} / \mathrm{dl})$ & $47.52 \pm 15.3$ & $40.31 \pm 10.71$ & 1.82 \\
\hline
\end{tabular}

LDL-C, low density lipoprotein cholesterol; HDL-C, high density lipoprotein cholesterol, ${ }^{*}$ Significant $\mathrm{P}$ values $(\mathrm{P}<$ $0.05)$ when compared with control group.

\section{Thyroid function tests in cardiac groups:-}

Our study showed that, there were statistically significant higher levels of TSH in ischemic cardiac group (3.20 \pm 2.99) compared with hypertensive cardiac group $(2.01 \pm 2.43)(\mathrm{p}<0.05)$. On the contrary there were no significant different as regard free T3 and T4 levels among studied groups (figure 1).

Figure 1:- thyroid function tests in cardiac groups

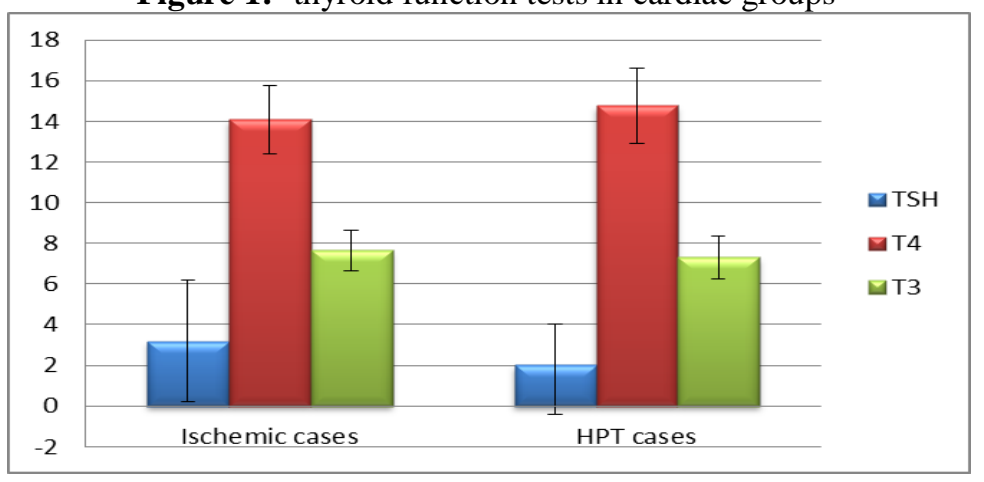

The prevalence of subclinical hypothyroidism in cardiac group:-

In all cardiac group was (22\%); in ischemic group (26\%) and in hypertensive group (18\%) (Figure 2).

Figure 2:- prevalence of subclinical hypothyroidism $(\mathrm{SCH})$ in both ischemic and hypertensive cardiac elderly

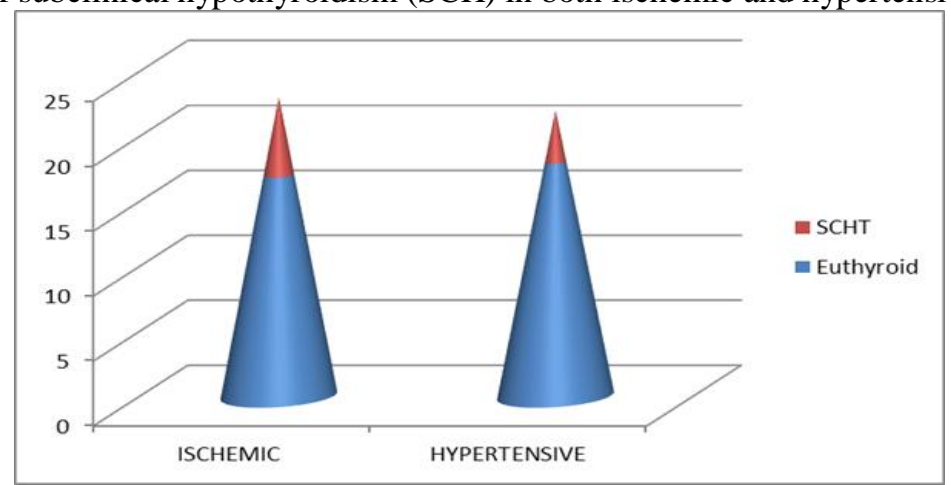


The prevalence of coronary artery occlusion in ischemic cardiac group In ischemic cardiac group ( $\mathrm{n}=23)$, there were; normal (62.2\%), single vessel disease (24.4\%), two vessel diseases (11.2\%) and three vessels (2.2\%) (Figure .

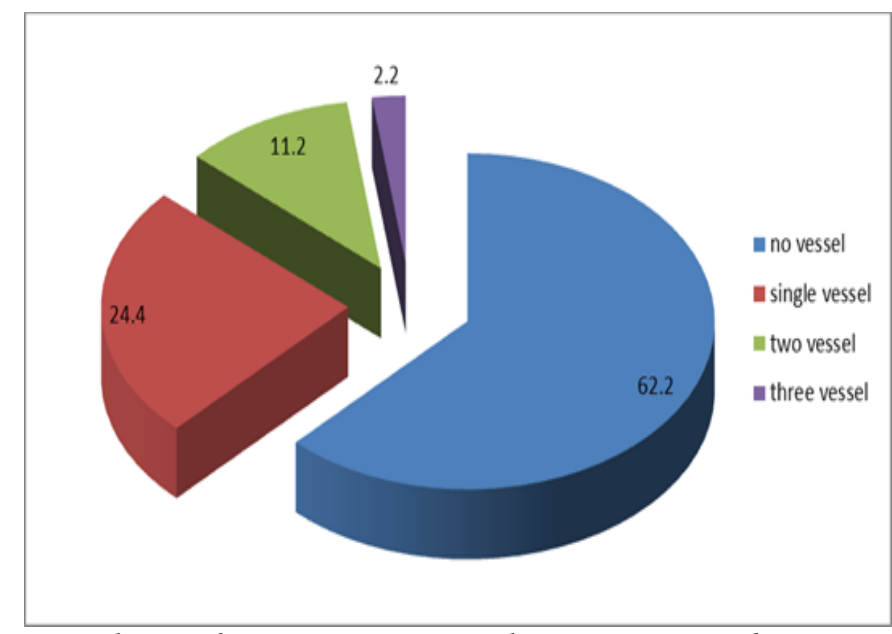

Figure 3:- prevalence of coronary artery occlusion among ischemic cardiac group

Pearson correlation analyses in ischemic cardiac patients:-

In ischemic cardiac patients $(\mathrm{n}=23)$, there were significant positive correlation between TSH levels and number of coronary artery occlusion $(r=0.307, \mathrm{P}<0.05)$. (Figure 4$)$.

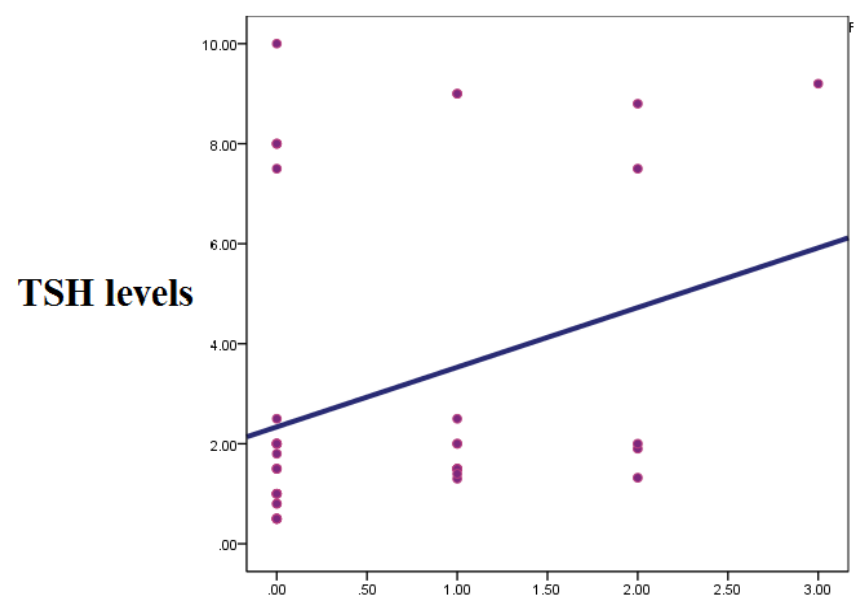

numbers of coronary artery occlusions

Linear regression analyses in ischemic cardiac patients to test the influence of the main independent variables against TSH levels (dependent variable).

In ischemic group, stepwise linear regression analysis showed that, serum TSH levels were independently correlated with TC, TG, LDL and HDL, $(\mathrm{P}<0.05)$ (Table 3).

Table 3:- Linear regression analyses test the influence of the main independent variables against TSH levels (dependent variable) in ischemic cardiac patients.

\begin{tabular}{|l|l|l|l|c|}
\hline \multirow{2}{*}{} & \multicolumn{2}{|c|}{ Unstandardized Coefficients } & \multirow{2}{*}{$\begin{array}{c}\text { Standardized } \\
\text { Coefficients }\end{array}$} & \multirow{2}{*}{ P value } \\
\cline { 2 - 4 } & \multicolumn{2}{|c|}{ B } & Std. Error & \multicolumn{2}{c|}{ B } & \\
\hline Age & 0.041 & 0.093 & 0.023 & 0.439 \\
\hline FT4(ng/dl) & 0.136 & 0.100 & 0.077 & 1.359 \\
\hline FT3(pg/ml) & 0.208 & 0.159 & 0.068 & 1.308 \\
\hline
\end{tabular}




\begin{tabular}{|l|l|l|l|l|}
\hline Total cholesterol $(\mathrm{mg} / \mathrm{dl})$ & 0.477 & 0.129 & 3.923 & $<0.01$ \\
\hline Triglycerides $(\mathrm{mg} / \mathrm{dl})$ & 0.070 & 0.028 & 0.769 & $<0.05$ \\
\hline LDL cholesterol $(\mathrm{mg} / \mathrm{dl})$ & 0.605 & 0.156 & 6.037 & $<0.01$ \\
\hline HDL cholesterol $(\mathrm{mg} / \mathrm{dl})$ & 0.442 & 0.168 & 2.266 & $<0.05$ \\
\hline
\end{tabular}

LDL-C, low density lipoprotein cholesterol; HDL-C, high density lipoprotein cholesterol. TSH, thyroid stimulating hormone; FT3 free triidothyronine, FT4; free thyroxine , Significant P values $(\mathrm{P}<0.05)$ when compared with control group.

\section{Discussion:-}

Increasing evidence suggests that Overt hypothyroidism is one of modifiable causes of atherosclerosis, even mild hypothyroidism may also contribute to atherosclerosis $(13,14)$, particularly if serum TSH is above $10 \mathrm{mIU} / \mathrm{L}(15)$. Evidence also suggests that levothyroxine treatment of subclinical hypothyroidism may have advantageous effects on endothelial function $(16,17)$ and carotid artery intima-media thickness, $(18,19)$ which are early markers of atherosclerosis.

In this study we found that cardiac patients group with thyroid abnormalities had significantly higher values of systolic and diastolic blood pressure, fasting blood glucose, total cholesterol and LDL cholesterol as compared to controls, similarly, Napoli et al.,(2010) found that, the alternations of cardiac performance, systemic blood pressure and lipid profile had been described in subclinical hypothyroidism patients, supporting a biologically role for mild hypothyroidism in the development of early atherosclerosis (20).

According to our results, there were statistically significant higher levels of cholesterol and LDL in case group compared with control group, in ischemic group; there were higher levels of TC and LDL than hypertensive group. Also, when we stratified ischemic group to euthyroid and subclinical hypothyroidism; we detected higher levels of TC and LDL in subclinical hypothyroidism patients compared with euthyroid. Similar results observed by Canaris et al.(2000) they showed that patients with subclinical hypothyroidism had slightly but significantly higher total cholesterol and LDL-C levels compared with controls (3). Linear regression analyses in ischemic cardiac patients showed that, serum TSH levels were independently correlated with TC, TG, LDL and HDL, $(\mathrm{P}<0.05)$.

The main finding of our study showed that, there were statistically significant higher levels of TSH in case group compared with control group. Moreover, in ischemic group, there were higher levels of TSH than hypertensive group. On the contrary, FT4 and FT3 levels were in normal levels and their levels were non -significant between different groups.

According to our studies, the prevalence of subclinical hypothyroidism in all cardiac group was (22\%); in ischemic group (26\%) and in hypertensive group (18\%) and to the best of our knowledge these results were higher than general elderly population especially in ischemic group and higher prevalence may be one of the risk factors for cardiovascular disease parse or due to dyslipidemia associated with subclinical hypothyroidism.

Several observational studies found that the prevalence of subclinical hypothyroidism ranges from 5 to $15 \%$ of the general population, with a significant increase in the older age classes, especially in women with thyroid autoimmunity and rich diet iodine intake (21). The wide range of prevalence rates could be related to the heterogeneity of the population of published trials, which differs according to patient's age, lifestyle, comorbidity, treatment, ethnicity, as well as the limits of normal TSH range utilized in each study (22).

In the present study, the prevalence of coronary artery occlusion in case group were; normal (62.2\%), single vessel disease $(24.4 \%)$, two vessel diseases $(11.2 \%)$ and three vessels $(2.2 \%)$.

Similar results observed by a meta-analysis of 10 pooled studies enrolling 14449 participants found a pattern of moderately increased risk for CHD and mortality in subclinical hypothyroidism patients together with evidence for statistical heterogeneity. Specifically, they found a relationship between subclinical hypothyroidism and CHD according to either the mean age of enrolled individuals (above or below $65 \mathrm{y}$ ) or the degree of serum TSH elevation (above or below10mIU/L) (23). 
In agreement with our results, a cross-sectional study of 1101 individuals aged 65 years showed a significantly higher prevalence of CHD only in subclinical hypothyroidism patients with the highest serum TSH levels (> $10 \mathrm{mIU} / \mathrm{L})(24)$.

Finegold et al. (2012) confirmed that, age is by far the most important risk factor in developing cardiovascular or heart diseases, with approximately a tripling of risk with each decade of life. It is estimated that 82 percent of people who die of coronary heart disease are 65 and older. At the same time, the risk of stroke doubles every decade after age 55 (25). Similarly, Ochs et al., (2008) found a relationship between subclinical hypothyroidism ,CHD risk factors, age of enrolled individuals (above or below $65 \mathrm{y}$ )and the degree of serum TSH elevation (above or below $10 \mathrm{mIU} / \mathrm{L}$ ) (23). On the contrary to our results, 3 meta-analyses of the most relevant prospective studies showed a positive association between subclinical hypothyroidism and CHD events and mortality, although less evident in older people (26).

Other study against our results; The Whickham Survey, an early population-based study of 2779 community dwelling individuals stratified by thyroid function and thyroid autoantibody status, found no association between subclinical hypothyroidism and CHD over 20 years of follow-up (27). Also, in addition, data from 3233 communitydwelling subjects older than 65 years did not show significant difference in the prevalence of CHD, stroke, or peripheral artery disease between subclinical hypothyroidism patients and euthyroid individuals (28).

Also, Somwaru et al., (2012) found that, a significant number of subclinical hypothyroidism subjects do not show progression, and some subjects experience serum TSH normalization. In this setting, the Cardiovascular Health Study, enrolling almost 4000 subjects aged over 65 years, recently confirmed that subclinical hypothyroidism persists in almost half of patients at 2- and 4-year follow-up, with high rates of reversion to euthyroidism in those with lower TSH concentrations ( $<7 \mathrm{mIU} / \mathrm{L}$ ) and negative serum thyroid peroxidase antibody titer (29).

Reanalysis of data from the Whickham Survey found a relationship between subclinical hypothyroidism and CHD events and mortality by including L-T4 replacement as covariate, at least in young adults (mean age, 49.9) (30).

We can conclude that the prevalence of subclinical hypothyroidism in all cardiac group was (22\%); in ischemic group (26\%) and in hypertensive group (18\%). Also, there was positive association between Subclinical Hypothyroidism, Hypertension, Dyslipidemia and CHD in elderly Patients there is positive association between SCH ,Hypertension, dyslipidemia (High Cholesterol and LDL) and number of coronary artery occlusion in elderly Patients.

\section{References:-}

1. Kevin Kinsella and David R. Phillips( 2005):.Global Aging, The challenge of success . Population Bulletins Volume 60. No.1

2. Cooper DS, Biondi B. Subclinical thyroid disease. Lancet. 2012;379:1142-1154.

3. Canaris Gay J, Manowitz Neil, Gilbert Mayor, et al(2000): The Colorado Thyroid Disease Prevalence Study. Arch Intern Med. ;160(4):526-534.

4. Monzani F, D i Bello V, Caraccio N,et al(2001): Effect of levothyroxine on cardiac function and structure in subclinical hypothyroidism: a double blind, placebo-controlled study. J Clin Endocrinol Metab. Mar;86(3):1110-5.

5. Brenta G, Schnitman M, Fretes O, et al(2003): Comparative efficacy and side effects of the treatment of euthyroid goiter with levo-thyroxine or triiodothyroacetic acid. J Clin Endocrinol Metab. Nov;88(11):5287-92.

6. Nanchen D, Gussekloo J, Westendorp RG, et al. (2012): Subclinical thyroid dysfunction and the risk of heart failure in older persons at high cardiovascular risk.J Clin Endocrinol Metab; 97:852-861.

7. Madathil A ,Hollingsworth KG, Blamire AM, et al.(2015): Levothyroxine improves abnormal cardiac bioenergetics in subclinical hypothyroidism: a cardiac magnetic resonance spectroscopic study. J Clin Endocrinol Metab. 2015 Apr;100(4):E607-10. doi: 10.1210/jc.2014-2942. Epub 2014 Dec 26.

8. Biondi B, Cooper DS. The clinical significance of subclinical thyroid dysfunction. Endocr Rev. 2008;29:76131.

9. Surks MI, Ortiz E, Daniels GH, Sawin CT, Col NF, Cobin RH, et al. Subclinical thyroid disease: scientific review and guidelines for diagnosis and management. JAMA. 2004;291:228-238. [PubMed]

10. Clin Lab Navigator: Thyroid function tests. Available from: http://www.clinlabnavigator.com/thyroid-functiontests.html (updated 2014 Dec 17). 
11. Friedewald WT, Levy RI, Fredrickson DS. Estimation of the concentration of low-density lipoprotein cholesterol in plasma, without use of the preparative ultracentrifuge. Clin Chem. 1972;18:499-502

12. Bemben DA, Hamm RM, Morgan L, et al (1994) Thyroid disease in the elderly. Predictability of subclinical hypothyroidism. J Fam Pract ;38(6):583-8.

13. Biondi, B. \& Cooper, D.S. (2008) The clinical significance of subclinical thyroid dysfunction. Endocrine Reviews, 29, 76-131.

14. Cappola, A.R. \& Ladenson, P.W. (2003) Hypothyroidism and atherosclerosis. Journal of Clinical Endocrinology and Metabolism, 88, 2438-2444

15. Rodondi, N., den Elzen, W.P., Bauer, D.C. et al. (2010) Subclinical hypothyroidism and the risk of coronary heart disease and mortality. Journal of the American Medical Association, 304, 1365-1374.

16. Razvi, S., Ingoe, L., Keeka, G. et al. (2007) The beneficial effect of L-thyroxine on cardiovascular risk factors, endothelial function, and quality of life in subclinical hypothyroidism: randomized, crossover trial. Journal of Clinical Endocrinology and Metabolism, 92, 1715-1723.

17. Taddei, S., Caraccio, N., Virdis, A. et al. (2003) Impaired endothelium-dependent vasodilatation in subclinical hypothyroidism: beneficial effect of levothyroxine therapy. Journal of Clinical Endocrinology and Metabolism, 88, 3731-3737.

18. Adrees, M., Gibney, J., El-Saeity, N. et al. (2009) Effects of 18 months of L-T4 replacement in women with subclinical hypothyroidism. Clinical Endocrinology (Oxford), 71, 298-303.

19. Monzani, F., Caraccio, N., Kozakowa, M. et al. (2004) Effect of levothyroxine replacement on lipid profile and intima-media thickness in subclinical hypothyroidism: a double-blind, placebo-controlled study. Journal of Clinical Endocrinology and Metabolism, 89, 2099-2106.

20. Napoli R, Guardasole V, Zarra E, et al. (2010): Impaired endothelial- and nonendothelial-mediated vasodilation in patients with acute or chronic hypothyroidism. Clin Endocrinol (Oxf); 72: 107-111.

21. Bremner AP, Feddema P, Leedman PJ, et al. (2012): Age-related changes in thyroid function: a longitudinal study of a community-based co-hort.J Clin Endocrinol Metab; 97:1554-1562

22. Klubo-Gwiezdzinska J, Wartofsky L. (2009): Thyrotropin blood levels subclinical hypothyroidism, and the elderly patient. Arch Intern Med; 169:1949-1951

23. Ochs N, Auer R, Bauer DC, et al. (2008): Meta-analysis: subclinical thyroid dysfunction and the risk for coronary heart disease and mortality. Ann Intern Med. 2008; 148:832-845

24. Lindeman R D, Romero L J, Schade DS, et al. (2003): Impact of subclinical hypothyroidism on serum total homocysteine concentrations, the prevalence of coronary heart disease (CHD), and CHD risk factors in the New Mexico Elder Health Survey. Thyroid; 13:595-600

25. Finegold JA, Asaria P, Francis DP. (2012): "Mortality from ischaemic heart disease by country, region, and age: Statistics from World Health Organisation and United Nations.". International journal of cardiology 168 (2): 934-945.

26. Rodondi N, den Elzen WP, Bauer DC, et al. (2010): Subclinical hypothyroidism and the risk of coronary heart disease and mortality. JAMA; 304:1365-1374.

27. Vanderpump MP, Tunbridge WM, French JM, et al. (1996): The development of ischemic heart disease in relation to autoimmune thyroid disease in a 20-year follow-up study of an English community. Thyroid; 6:155160

28. Cappola AR, Fried LP, Arnold AM, et al. (2006): Thyroid status, cardio-vascular risk, and mortality in older adults. JAMA; 295: 1033-1041

29. Somwaru LL, Rariy CM, Arnold AM, et al. (2012): The natural history of subclinical hypothyroidism in the elderly: the Cardiovascular Health Study. J Clin Endocrinol Metab; 97: 1962-1969.

30. Razvi S, Weaver JU, Vanderpump MP, et al. (2010): The incidence of ischemic heart disease and mortality in people with subclinical hypothyroidism: reanalysis of the Whickham Survey cohort. J Clin Endocrinol Metab; 95:1734-1740. 